\title{
NGHIÊN CỨU XÂY DỰNG CHƯƠNG TRİNH ĐÀO TẠO LIÊN KẾT THỰC HÀNH VÀ LÍ THUYẾT THEO TIÊU CHUẦN CDIO TRONG CHƯƠNG TRÌNH CÔNG NGHỆ KỸ THUẬT ĐIỆN TỬ
}

\author{
Nguyễn Duy $\operatorname{Nam}^{(*)}$ \\ (*) Thạc sĩ. Truờng Đại học Công nghệ Đồng Nai. Email:nguyenduynam@dntu.edu.vn
}

DOI: $10.37550 /$ tdmu.CFR/2021.01.101

\section{Tóm tắt}

Dự án nghiên cứu và xây dụng chương trình đào tạo thục hành theo chuẩn CDIO cho Chuoong trình Công nghệ Kỹ thuật điện tử đang được thử nghiệm tại DNTU. Để đào tạo ra nhũng kỹ su tài năng, một chương trình giảng dạy phù hợp, dựa trên nhu cầu thưc tế của doanh nghiệp đã và đang được phát triển. Khác với phương pháp truyền thống, lí thuyết và thực hành được sử dụng đồng thời để xây dưng chuơng trình mói theo giáo trình CDIO. Sư huớng dẫn đồng thời tù giảng viên và các kỹ su, chuyên gia trong ngành, muc đích đào tạo sinh viên với kế hoạch được cá nhân hóa. Các sinh viên tài năng sẽ được phân công giúp đõ bạn hoc. Phuoong pháp giảng dạy dựa trên vấn đề, dụa trên tình huống và dựa trên dụ án được điều chỉnh trong lớp với nhiều phương pháp đánh giá được sủi dụng. Cải cách CDIO trong chuơng trình Công nghệ kỹ thuật điện tử đã buớc đầu đạt được nhũng thành công.

Tù̀ khóa: thục hành CDIO, giáo dục kỹ thuật, ươm mầm tài năng

\section{1. Đặt vấn đề}

Ở Việt Nam, giảng dạy kiến thức theo khuôn mẫu luôn là cốt lõi trong giáo dục kỹ thuật truyền thống, việc giáo dục đạo đức nghề nghiệp và trách nhiệm đối với xã hội và môi trường bị bỏ qua. Do đó có khoảng cách rất lớn giữa yêu cầu của các doanh nghiệp hiện đại về nhân tài so với năng lực thực tế của sinh viên đã tốt nghiệp [1-3]. Dựa trên nghiên cứu sâu sắc về triết lý giáo dục kỹ thuật của CDIO [1] và tình hình thực tế của DNTU, một kế hoạch hoàn chỉnh về đào tạo bao gồm mục tiêu giáo dục, kế hoạch trau dồi, nhóm các khóa học, hệ thống thực hành và thí nghiệm, phương pháp và tiêu chuẩn kiểm tra và hệ thống kiểm soát chất lượng giáo dục trong môi trường hợp tác và cạnh tranh toàn cầu được hình thành, thiết kế, triển khai và vận hành trong chương trình Công nghệ kỹ thuật điện tử.

\section{Suy nghĩ về giáo dục kỹ thuật}

Trên nền tảng giáo dục kỹ thuật CDIO và kinh nghiệm cải cách giáo dục, phương thức đào tạo tài năng mới được phân lớp tự nhiên và cá nhân hóa theo năng khiếu và sở thích của 
sinh viên: khuyến khích phát triển cá nhân, tập trung vào phát triển chất lượng tổng hợp và kết hợp với hình thành ý tưởng - thiết kế - triển khai - vận hành. Bằng cách kết hợp ý tưởng giáo dục phù hợp với năng khiếu của sinh viên và phương thức giáo dục kỹ thuật CDIO.

Theo tiêu chuẩn của CDIO, một chương trình đào tạo nhân tài tổng hợp được xây dựng cẩn thận dựa trên các yêu cầu về kiến thức, năng lực và phẩm chất cho sinh viên của chúng tôi. Đề án đề xuất được xây dựng theo nguyên tắc của phương thức giáo dục phân lớp, phương án giáo dục cá thể hóa, nội dung giáo dục tích hợp và nhiều tiêu chuẩn đánh giá.

Trước hết, phương thức bồi dưỡng nhân tài truyền thống nhằm mục đích truyền đạt kiến thức được chuyển sang phương thức mới nhằm phát triển năng lực và phẩm chất của sinh viên. Chúng ta đều biết rằng mục đích chính của phương thức truyền thống là dạy sinh viên kiến thức chuyên ngành, tuy nhiên, mục đích của phương thức mới là giáo dục sinh viên đáp ứng các yêu cầu của một kỹ sư, chẳng hạn như nắm vững kiến thức chuyên sâu của nền tảng kỹ thuật, tinh thần đổi mới, hiểu được tầm quan trọng và tác động chiến lược của nghiên cứu và phát triển công nghệ đối với xã hội [4].

Thứ hai, nội dung của kế hoạch ươm mầm tài năng mới nhắm vào các yêu cầu chuyên môn của kỹ sư tương lai, như thiết kế kỹ thuật, phân lớp theo kiến trúc của hệ thống ứng dụng, các mô đun chức năng và các yếu tố cơ bản, tập trung vào sự phát triển được cá nhân hóa của sinh viên.

Thứ ba, tiêu chuẩn cũ để đánh giá vốn chỉ dựa trên một tiêu chuẩn và một phương pháp cho tất cả sinh viên. Tôi tin rằng mỗi sinh viên sẽ thành công nếu các em học để hiểu, học để trở thành và học cách làm theo sở thích và năng khiếu của mình.

Thứ tư, giải quyết vấn đề giảng viên thiếu kinh nghiệm thực tiễn, cần một kế hoạch trợ giảng đồng thời cho nhóm sinh viên, được thực hiện bởi giảng viên DNTU và kỹ sư chuyên ngành.

Sinh viên ghi danh vào chương trình kỹ thuật công nghệ kỹ thuật điện tử được chia thành tám sinh viên mỗi đội theo cách lựa chọn ngẫu nhiên, cố định trong 4 năm học kèm theo hai trợ giảng. Để phát triển các khả năng như tổ chức, điều hành và phối hợp..., mỗi thành viên phải lần lượt là trưởng nhóm trong suốt 4 năm học. Giám sát nhóm phải xây dựng kế hoạch giáo dục cho từng thành viên trong nhóm và cho cả nhóm. Các dự án thực tế cho nhóm được thực hiện để phát triển khả năng CDIO của sinh viên.

Thứ năm, những sinh viên nổi bật được chọn làm gia sư học tập của nhóm. Vì đây là người phù hợp hiểu và giải quyết những gì khó khăn đối với các bạn trong nhóm.

\section{Xây dựng chương trình tích hợp ươm mầm tài năng}

Trong quá trình xây dựng chương trình mới, phải tuân thủ các nguyên tắc của kế hoạch giáo dục cá nhân, nội dung tích hợp và nhiều tiêu chuẩn đánh giá để đạt được mục tiêu kiến thức, năng lực và phẩm chất cho người học. Một chương trình khung ươm mầm tài năng CDIO cá nhân hóa dựa trên năng khiếu và sở thích được phát triển sao cho phù hợp với vai trò chuyên môn của kỹ sư. Theo khuôn khổ này, các nhóm khóa học được tổ chức từ 
trên xuống dưới hoặc ngược lại. Trong phương pháp tổ chức nhóm khóa học từ dưới lên, kiến thức cơ bản được cung cấp trước kiến thức chuyên môn, kiến thức vi mô được học trước vĩ mô. Điều này dẫn đến việc sinh viên mới bối rối không biết lý do tại sao mình cần học các học phần và ứng dụng của chúng. Tuy nhiên, phương pháp tổ chức các nhóm khóa học từ trên xuống được hướng dẫn bởi thiết kế kỹ thuật thực tế và toàn bộ khái niệm hệ thống kỹ thuật được xem xét trước tiên, sau đó từ vĩ mô đến vi mô, từ hệ thống đến cục bộ và từ kiến thức chuyên ngành liên quan tới dự án đến kiến thức cơ bản tương ứng.

Minh họa trong hình 1 , trên cơ sở phân tích chi tiết các yêu cầu chuyên môn của kỹ sư điện tử, tôi chọn thử nghiệm ba thiết kế dựa trên vai trò là kiến trúc sư hệ thống, nhà thiết kế (bao gồm thiết kế mạch tích hợp và thiết kế phần mềm nhúng) và kỹ sư ứng dụng điện tử.

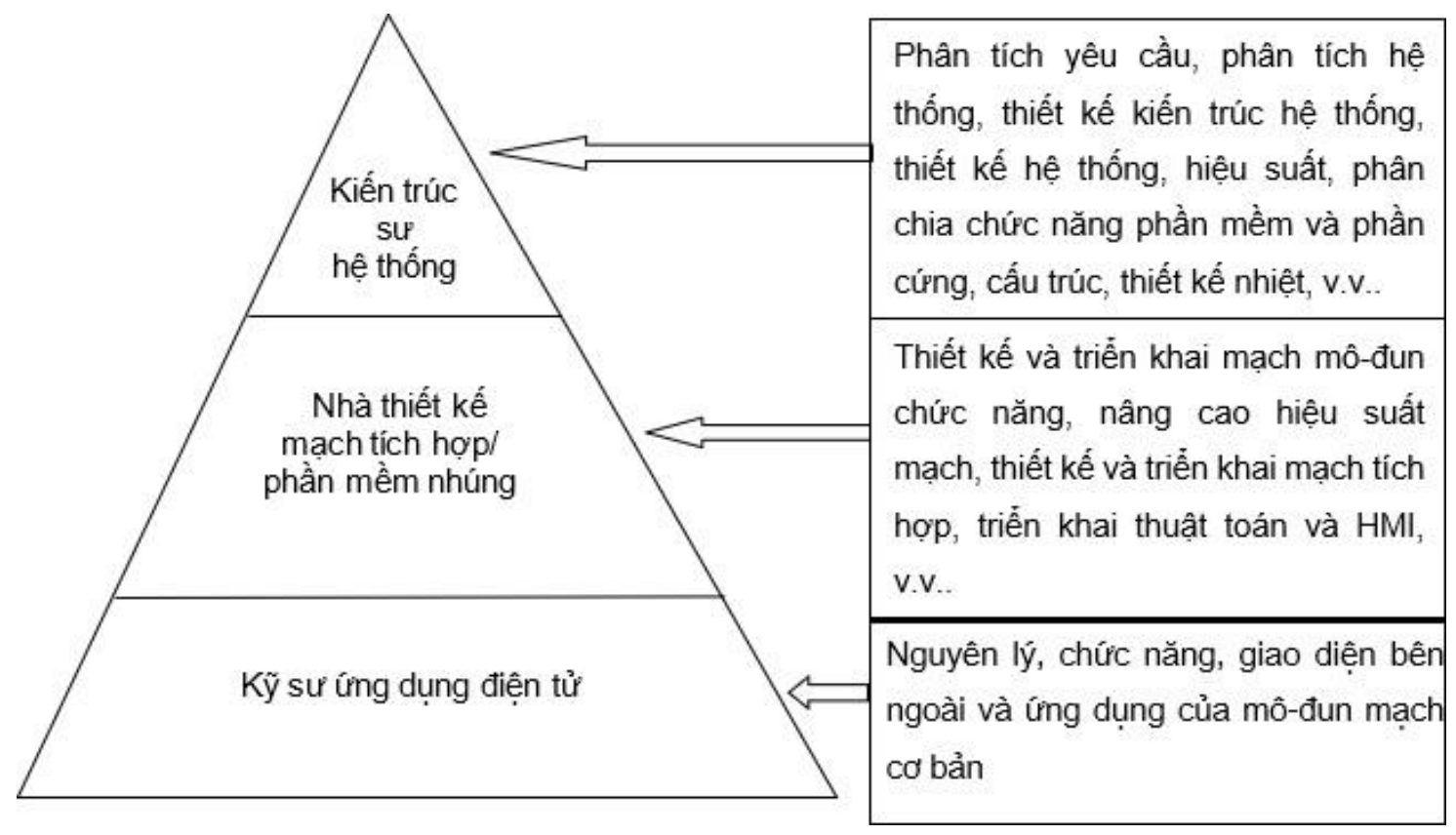

Hinh 1. Các yêu cầu cơ bản và thiết kế phù hợp cho giáo dục dụa trên vai trò.

Đây là mục tiêu mà sinh viên có thể đạt được sau khi học tập từng bước có hệ thống. Tất cả sinh viên ban đầu học để trở thành một kỹ sư ứng dụng điện tử, một số trong đó có thể dần trở thành nhà thiết kế và chỉ có số ít có thể trở thành kiến trúc sư hệ thống. Yêu cầu cơ bản của mỗi vai trò bao gồm kiến thức, công cụ và kỹ năng cần thiết. Kiến thức cần có bao gồm học phần kiến thức nền tảng, kiến thức mở rộng và các học phần kiến thức nâng cao. Tất cả các mô đun kiến thức là cốt lõi của các nhóm khóa học này.

Trên cơ sở kỹ sư ứng dụng điện tử, sinh viên có thể lựa chọn các mô đun kiến thức liên quan đến thiết kế khác nhau tùy theo năng khiếu và khả năng của mình để hình thành kế hoạch trau dồi bản thân hướng tới mục tiêu trở thành nhà thiết kế.

Bằng phương pháp này, vấn đề giáo dục cá nhân theo năng khiếu của sinh viên được giải quyết một cách hiệu quả. Ở lớp học truyền thống, việc tập trung nhiều hơn vào các kỹ thuật phân tích, tính toán, quan tâm nhiều hơn đến việc hoàn thiện lý thuyết, bỏ qua việc dạy các phương pháp tư duy và ứng dụng kỹ thuật trong thực tế. Sau khi cải cách, kiến thức nền và công nghệ hiện đại được cân bằng, lý thuyết cơ bản và phương pháp tư duy được thực 
hành đồng thời trên lớp.

\section{Triển khai và vận hành chương trình đã đề xuất}

Trong quá trình cải cách giáo dục kỹ thuật, tất cả chúng ta đều nghĩ rằng về quan điểm nội dung có rất ít sự khác biệt giữa Việt Nam và các nước phương Tây. Ví dụ, để đáp ứng các yêu cầu của $\mathrm{ABET}$, hầu hết tất cả các trường học ở Hoa Kỳ đều điều chỉnh nội dung của khóa học và các tính năng khác nhau của chúng được phản ánh trong các khóa học của họ.

Mặc dù mục tiêu đào tạo kỹ sư có trình độ rất rõ ràng, nhưng sự khác biệt rất lớn tồn tại về cách giáo dục sinh viên có các kỹ năng và phẩm chất nghề nghiệp, triết lý giáo dục, phương pháp sư phạm và phương thức học tập của sinh viên. Những vấn đề sau đây được xem xét và suy nghĩ lại một cách nghiêm túc: làm thế nào để giáo dục mỗi sinh viên trở thành một nhân tài khi sự khác biệt tồn tại? Làm thế nào để đánh giá khả năng tích hợp của sinh viên? Làm thế nào để phát triển hệ thống đảm bảo chất lượng của giáo dục kỹ thuật? Làm thế nào để đương đầu với mối quan hệ giữa nghiên cứu và giảng dạy? Làm thế nào để kết hợp lý thuyết với thực hành một cách hiệu quả? Làm thế nào để hợp tác với tính chính trực cao trong khi có sự cạnh tranh? Sau khi thảo luận và suy nghĩ sâu sắc, một kế hoạch cụ thể hóa đã được xây dựng để trả lời những câu hỏi này.

\subsection{Cải cách hệ thống giáo trình và tối uu hóa nội dung chuơng trình học}

Để thực hiện đề án, chúng ta phải cải cách hệ thống giáo trình và tối ưu hóa nội dung chương trình giảng dạy. Việc giáo dục kiến thức cơ bản về kỹ thuật, khả năng cá nhân, kỹ năng giao tiếp, làm việc nhóm và kỹ thuật hệ thống được thực hiện bằng cách kết hợp với các dự án toàn diện, có liên quan đến nhóm khóa học và các dự án trong khóa học.

Trong hình 2 thể hiện cách tối ưu hóa nội dung và cấu trúc chương trình công nghệ điện tử trong chương trình công nghệ kỹ thuật điện tử.

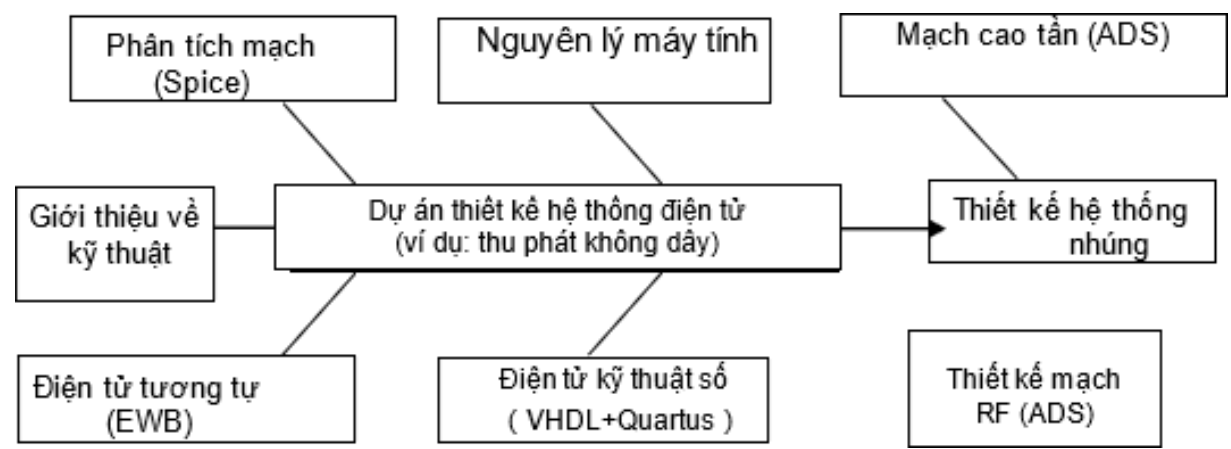

Hinh 2. Vi dụ tối ưu hóa nhóm giáo trình công nghệ điện tử

Bộ giáo trình Công nghệ điện tử bao gồm: phân tích mạch, điện tử tương tự, điện tử kỹ thuật số, mạch cao tần, nguyên lý máy tính, cơ bản của thiết kế điện tử, thiết kế điện tử nâng cao và thiết kế hệ thống nhúng. Tất cả các nội dung trong khóa học được lựa chọn và sắp xếp dựa trên nhu cầu thực tiễn của doanh nghiệp. Điều này khiến sinh viên phải học bằng các câu hỏi và phải tìm ra cách giải quyết vấn đề. Vì vậy, trong chương trình này, giảng viên chỉ là người hướng dẫn hoặc trợ giúp và sinh viên phải là người làm chủ việc học. 
Đối với mỗi khóa học, ngoài các yêu cầu thông thường, cần có thêm các yêu cầu khác như mô tả khóa học, mối quan hệ với các khóa học khác, đối tượng của khóa học, nội dung khóa học, kết quả học tập và phương pháp sư phạm chính, số giờ tín chỉ và kỳ thi cần mô tả chi tiết trong mô tả khóa học.

\subsection{Xây dựng cấu trúc thục hành tích hợp}

Mặc dù rất coi trọng việc xây dựng hệ thống thực hành nhưng chương trình hiện tại vẫn có khoảng cách lớn so với CDIO, tất cả các dự án thực hành hiện hữu đều được phát triển độc lập, thiếu quy hoạch và thiết kế hệ thống. Hai hoặc nhiều dự án cấp cao, dự án nền tảng và dự án cốt lõi, được yêu cầu trong CDIO. Dựa trên dự án thiết kế toàn diện đã có từ trước bao gồm các dự án thiết kế trong khóa học, các dự án thiết kế ba cấp độ cho nhóm sinh viên. Dự án cấp độ đầu tiên bao gồm phạm vi của phần lớn các khóa học chính và liên quan nhiều đến chương trình công nghệ kỹ thuật điện tử. Dự án cấp hai bao gồm một số khóa học chính và dự án cấp ba là dự án trong khóa học, chỉ để giúp sinh viên hiểu sâu sắc nội dung của khóa học.

Hai dự án cấp một trong đó một hệ thống hoàn chỉnh sẽ được thực hiện trong suốt bốn năm nghiên cứu. Sinh viên sẽ được đào tạo có hệ thống thông qua việc lên ý tưởng, thiết kế, triển khai và vận hành một dự án. Trong dự án nền tảng, một sản phẩm được sử dụng để sinh viên tháo rời và hiểu nguyên lý hoạt động của nó. Điều này sẽ khơi dậy trí tò mò của sinh viên và hoạt động thiết kế lại sẽ thể hiện tư duy đổi mới của các em và kích thích sinh viên học tập môn học chuyên ngành. Trong hình 3 , các thành phần của dự án cấp một của CDIO được liệt kê.

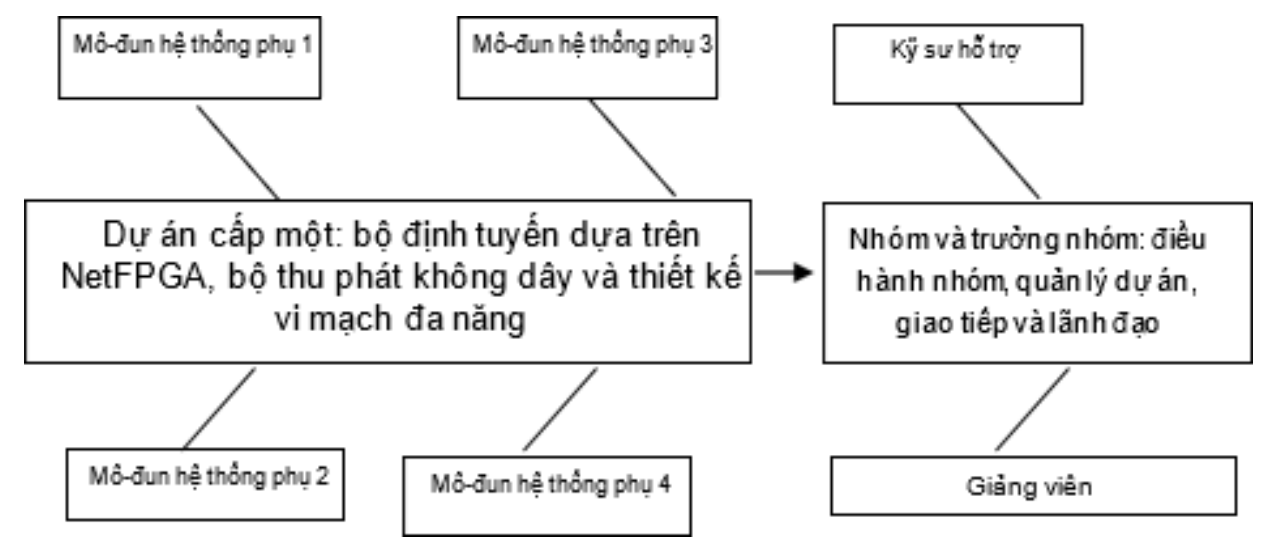

Hình 3. So đồ thành phần của dụ án CDIO cấp một

Dự án cấp hai dựa trên nhóm khóa học tạo thành mô đun hệ thống con của dự án cấp một. Khả năng sử dụng các kiến thức liên quan được rèn luyện và khả năng tư duy sáng tạo được trau dồi trong quá trình xây dựng dự án. Bốn đến sáu dự án cấp hai phải được hoàn thành trong bốn năm học.

Dự án cấp độ thứ ba nằm trong dự án khóa học và được thiết lập để hiểu thêm kiến thức trong khóa học. Khả năng chuyên môn cho kỹ sư tương lai được rèn luyện trong quá trình thực hiện các dự án này trong đội ngũ sinh viên. Mỗi thành viên trong nhóm sẽ là trưởng nhóm một lần và khả năng lãnh đạo, quản lý và kỹ năng giao tiếp được rèn luyện trong quá trình phát triển dự án. 
Nhìn chung, đề án ươm mầm tài năng được đề xuất có những điểm khác biệt so với đề án cũ.

1. Bằng cách giới thiệu khóa học một cách trực quan sinh động, vận dụng linh hoạt các phương pháp cần thiết trong giảng dạy đã kích thích sự quan tâm, ham học hỏi của sinh viên đối với ngành Công nghệ kỹ thuật điện tử ở DNTU.

2. Số lượng khóa học giảm xuống, kiến thức nền tảng được nhấn mạnh và tối ưu hóa nội dung. Nội dung và các yêu cầu cụ thể đối với môn Toán, Vật Lý, tiếng Anh và bài tập được cung cấp rõ ràng.

3. Các dự án thực hành ba cấp độ được phát triển để đào tạo khả năng chuyên môn của kỹ sư tương lai. Tất cả sinh viên đều được tham gia và đóng góp vào kết quả chung của dự án.

\subsection{Hệ thống lại nội dung giao trình}

Nội dung giáo trình được sắp xếp lại theo hình thức cơ bản và nâng cao. Trong phần cơ bản, cần sắp xếp nội dung của khóa học theo thứ tự nguồn gốc căn bản, nhiệm vụ, phương pháp thực hiện, sơ đồ mạch điển hình, môi trường ứng dụng điển hình, đo lường hiệu suất và các công cụ cần thiết bao gồm phần mềm và thiết bị đo. Tất cả sinh viên đều phải học phần kiến thức này. Trong phần nâng cao, các kiến thức mở rộng, cải thiện hiệu suất, phương pháp đánh giá giáo dục thực hành, sự tiến bộ của công nghệ và tài liệu đọc thêm được cung cấp cho sinh viên tiềm năng.

\subsection{Phưong pháp dạy học}

Tất cả các phương pháp giảng dạy lấy sinh viên làm trung tâm đều được khuyến khích và thực hành, các phương pháp giảng dạy dựa trên dự án và dựa trên vấn đề. Điều cần thiết là giảng viên phải kết hợp vấn đề khoa học với vấn đề thực hành kỹ thuật để đặt ra đúng vấn đề mà sinh viên cần giải quyết. Khuyến khích việc sử dụng công nghệ mới tốt cho việc giảng dạy. Sinh viên nên chuyển cách học thụ động sang học chủ động và tìm cách giải quyết vấn đề do giảng viên đưa ra. Học tập tích cực bao gồm học tập hợp tác, thảo luận nhóm, tranh luận và thí nghiệm tự thiết kế. Thói quen học tập tốt là điều quan trọng đối với sinh viên, không những thế để nâng cao năng lực chuyên môn đối với với người kỹ sư thì việc học tập suốt đời là điều quan trọng nhất.

\subsection{Cải cách thi củ}

Việc đánh giá kết quả học tập của sinh viên rất khó khăn. Chỉ có thể kiểm tra kiến thức của sinh viên trong chủ đề cụ thể. Tuy nhiên, thật khó để đánh giá khả năng thực hành, giao tiếp và năng lực quản lý. Phải tìm ra phương pháp kiểm tra linh hoạt và đa dạng để đánh giá kết quả học tập. Ví dụ, kỹ năng giao tiếp được đánh giá bằng cách viết, báo cáo kỹ thuật, soạn thảo và trình bày Power Point. Bộ tiêu chuẩn đánh giá tổng hợp đang được phát triển thêm.

\section{Kết luận}

Chương trình giảng dạy tích hợp, dựa trên nhu cầu thực tế của doanh nghiệp, đã và đang được phát triển. Nội dung giáo trình được sắp xếp lại. Các dự án thực hành ba cấp độ 
được triển khai kết hợp với sự hỗ trợ từ kỹ sư, chuyên gia bên ngoài. Đề án kiểm tra chất lượng dạy và học có sự đổi mới, danh sách các khả năng mà sinh viên tốt nghiệp cần có đang được xây dựng. Thực tế, ba năm qua cho thấy rằng thực hành $\mathrm{CDIO}$ trong chương trình Công nghệ kỹ thuật điện tử tại DNTU đã gặt hái được một số thành công đáng khích lệ. Việc cải cách ngày càng được nhiều sinh viên đón nhận, số lượng giảng viên tham gia xây dựng CDIO tăng dần sẽ giúp sinh viên học được cách học, để hiểu biết, để cùng chung sống và phát triển [5].

\section{Tài liệu tham khảo}

[1] Binling Gu, Reform and development of higher engineering education in china, Research on higher engineering education, 2004.5

[2] Zheng Li and Feng Lin, Trends of development of education of engineering, view from nature of engineering, Research on higher engineering education, 2007.2

[3] Educating the Engineer of 2020: Adapting Engineering Education to the New Century, Washington DC: The National Academies Press, 2005.

[4] Edward F. Crawley, Johan Malmqvist, Soren Ostlund, Doris R. Brodeur, Rethinking Engineering Education The CDIO Approach, 2007, Springer Science+Business Media. 